\title{
The Formation of the Self. Nietzsche and Complexity
}

\section{Paul Cilliers, ${ }^{1}$ Tanya de Villiers and Vasti Roodt}

\author{
Department of Philosophy, University of Stellenbosch, \\ Private Bag X1, Matieland, 7602, South Africa
}

\begin{abstract}
:
The purpose of this article is to examine the relationship between the formation of the self and the worldly horizon within which this self achieves its meaning. Our inquiry takes place from two perspectives: the first derived from the Nietzschean analysis of how one becomes what one is; the other from current developments in complexity theory. This two-angled approach opens up different, yet related dimensions of a non-essentialist understanding of the self that is nonetheless neither arbitrary nor deterministic. Indeed, at the meeting point of these two perspectives on the self lies a conception of a dynamic, worldly self, whose identity is bound up with its appearance in a world shared with others. After examining this argument from the respective viewpoints offered by Nietzsche and complexity theory, the article concludes with a consideration of some of the political and ethical implications of representing our situatedness within a shared human domain as a condition for self-formation.
\end{abstract}

\section{Introduction}

A short aphorism from the second volume of Human, All Too Human reads: "In solitude the solitary man consumes himself, in the multitude the many consume him. Now choose" (Nietzsche HAH II, 348). ${ }^{2}$ So as to leave us in no doubt about what is involved in this choice, Nietzsche inscribes his maxim with the title: "From the land of the cannibals". His point, one could argue, is precisely that one cannot choose. To embark on either course - retreating entirely into solitude or becoming passively immersed in communality - is to lose oneself. What is at stake here is this problematic relationship between the self and the crowd, between solitude and worldliness. Nietzsche is thus engaged with the general problem of the formation of the self. How does the self come to be so that we cannot deny its independent existence (and consequently acknowledging it as a bearer of responsibility), yet recognise its inevitable social embeddedness? In this article we are interested in the possibility that the thinking selfhood lies between the two extremes of solitude or solipsism on the one hand, and unilinear social determination on the other - not as their dialectical resolution into a higher unity, but as a tightrope walk between two kinds of dissolution.

1 To whom correspondence should be addressed (e-mail: <FPC@sun.ac.za>. This author also acknowledges the financial assistance of the National Research Foundation: Social Sciences and Humanities of South Africa towards this research, as well as the support of the Institute for the Study of Coherence and Emergence (ISCE) in Boston, USA. Opinions expressed and conclusions arrived at are those of the authors, and are not necessarily to be attributed to the National Research Foundation or to ISCE.

2 Nietzsche's works are identified by their English-language acronyms, followed by the relevant section number, unless otherwise indicated. Where deemed necessary, we have made minor alterations to the translations. 
In the so-called "post-modern" aftermath of Nietzsche's decentralisation of the metaphysical subject, a non-essentialist understanding of the self may seem fairly commonplace. For those familiar with the work of, among others, Foucault, Derrida, Lyotard and Lacan, it is easy - perhaps too easy - to talk about the decentred or fragmented self. For those not familiar with these discourses, as well as those who are critical of them, such an understanding of the self is not self-evident. From their perspective, the non-essentialist conception of the self represents the dissolution of morality, or its descent into relativism. ${ }^{3}$ If the self is a slippery affair, it becomes difficult to account for moral agency and to ascribe moral responsibility. It is worthwhile, therefore, to develop a non-essentialist understanding for the self from a perspective that would be more acceptable to those who are less inclined to accept arguments with a post-modern flavour. Such an argument can be made, we propose, from the perspective of complexity theory.

Complexity theory - not to be confused with chaos theory or cybernetics (see Cilliers 1998: viii-ix) - grew out of formal, scientific attempts to deal with a complex world. Although there were initial hopes that we would be able to develop theories that would help us to come to grips with complex phenomena in an objective way, the study of complex systems has rather confronted us with the limits of scientific knowledge (Cilliers 2000, 2001). As will be shown in more detail later, this means that we cannot avoid normative elements when dealing with complexity. This acknowledgement of the limits of objective knowledge implies that we can start with a rigorous, scientific form of analysis, and still arrive at an understanding that is neither mechanical nor final.

What we are attempting to show in this paper is how arguments from complexity can be used to develop an understanding of the self that bears a marked affinity with that of Nietzsche. At first glance, these two perspectives may appear somewhat disparate. Both, however, are concerned with the limits of our understanding of the self. This entails that the formation of the self can never be a completed process. On the one hand, our aim is then to show how a reflection on Nietzsche's critical philosophy dovetails with contemporary arguments on complexity in a way that casts new light on the relationship between order and multiplicity, solitude and communality, self and world. On the other hand, we also hope to provide an argument for an understanding of the self, similar to that of Nietzsche, which does not depend on the acceptance of his philosophical project.

By relating Nietzsche's thinking about the constitution of the self to particular insights derived from complexity theory, we thus offer two arguments for developing an understanding of self-formation as an event that is neither arbitrary nor determined. Our ultimate intention is to demonstrate that this way of thinking about the self does not operate simply on the level of individual psychology or scientific theory, but impacts on the way in which we conceive of our relations to others in the world. We propose to establish, in other words, the extent to which the question of who or what one is, is necessarily also a question of ethical and political praxis.

In the first section of the article we explore Nietzsche's understanding of selfformation - that is to say, the conditions under which one moulds a self, perhaps even fabricates a self, and thus becomes what one is. This issue is explored in relation to

3 Consider, for instance, Alasdair MacIntyre's critique of non-essentialist morality as a superficial emotivism that has taken root in the aftermath of the loss of a meaningful, pre-Enlightenment morality morality "as it once was" (MacIntyre 1992:22). 
Nietzsche's portrayal of the inter-human horizon within which this self achieves its meaning, and which he designates as "the world". This domain can be characterised as a "space of appearance" (a formulation borrowed from Hannah Arendt), with the dual qualities of phenomenality: allowing us to appear to others in a shared domain beyond the self, and provisionality: designating the fragility and contingency of the condition of our appearance.

In the second part of the article the perspective shifts to that of complexity theory. A brief introduction to this field argues that complex systems can only be understood in relational terms, and therefore cannot be given a complete and final description. The social system - "the world" or the "space of appearance" - is complex. The self comes to be in interaction with this complexity, while simultaneously contributing towards it. There is thus a tension between the self as constituted in the social system, and the system as something that is a result of the action of selves.

The third and final section examines specific ethical-political implications of this tension as it is theorised in both sets of arguments. From their different perspectives, both Nietzschean and complexity theory undermine the essentialist account of the self as well as social constructivist or deterministic notions of the self as a mere function or product of its environment. This account of the complex radicalises the tension between, and thus the precariousness of, both self and world; the unpredictability, instability and provisionality of the "system" at any one point. We aim to demonstrate that this conception of the self as something which is in perpetual formation through interaction with the world is political through and through, and that it is bound up with an ethics which is neither relativistic nor absolutist.

\section{Nietzsche and the formation of the self}

Even the most glancing encounter with Nietzsche's writings will uncover an insistence that the self is a fiction, that the belief in a unitary subject is a result of the grammatical seduction perpetrated by the category of the first person singular. And yet, he is equally insistent that we are able to give form to ourselves, indeed, that we ought to do so. This apparent contradiction - that one needs to become a self and that this very self does not exist except as a fiction or illusion - is bound up with the consideration of how one becomes who one is. To this end, it is worthwhile to examine Nietzsche's portrayal of action as a mode of self-formation, and the relation between action, memory and memory's necessary counterpart: forgetfulness. This inquiry will serve in turn to clarify Nietzsche's understanding of the indeterminacy of all identity, as well as the necessary, yet ambiguous relationship between self and world.

Two illuminating quotations from Human, All Too Human provide a valuable starting-point for the above considerations:

Everyone possesses inborn talent, but few possess the degree of inborn and acquired toughness, endurance and energy actually to become a talent, that is to say to become what he is: which means to discharge it in works and actions (HAH I, 263).

Active, successful natures act, not according to the dictum "know thyself", but as if there hovered before them the commandment: will a self and thou shalt become a self. - Fate seems to have left the choice still up to them; whereas the inactive and contemplative cogitate on what they have already chosen, on one occasion, when they entered into life (ibid. II, 366). 
Nietzsche is clearly suggesting that identity involves a kind of praxis. One does not become a self merely by virtue of conceptualising a character, or by allowing a given psychic reality to take external form - that is to say, precisely not by virtue of the Socratic "know thyself". On the contrary, what one is emerges from how one acts. In this sense, Nietzsche presents us with a performative account of identity, in terms of which the self is a dynamic formation that depends on performance, in the same way as the dancer who cannot be separated from the dance.

Seen in this light, not to perform, to refrain from action, is not a kind of negative freedom, a negation of all identity. Rather, it is the condition under which one is forced to submit to an identity that is imposed from without (cf. Villa 1992: 284). Nietzsche skilfully demonstrates this point in his genealogical exposition of master and slave morality in The Genealogy of Morals, where he argues that the distinction originates in a schism between two experiences of agency. Master morality emerges from an experience of an excess of strength that knows how to vent itself in deeds, and reserves the epithet "bad" for those who lack the capacity for action. Slave morality emerges among those who are incapable of discharging themselves in action, and who sublimate their secret self-disgust in a mode of evaluation according to which the active, commanding human being is evil, power is evil, self-affirmation is evil, and the lack of all of these capacities, weakness, the suspension of the will is baptised as "good" (GM II, 10). ${ }^{4}$ The former mode of evaluation originates with those who act, who give form to themselves, while the secondary, derivative, slavish moral code emerges with those who are acted upon.

It is important, however, not to misunderstand Nietzsche on this point: he does not portray self-formation as a purely arbitrary exhibition of activity. In his account, the emergence of identity is predicated on both the dynamics of performance and the constancy of memory, for it is only by remembering what one has done that it becomes possible to sustain a self over time. Nietzsche describes this in terms of the capacity to sustain promises, which requires "a real memory of the will: so that between the original "I will", "I shall do this" and the actual discharge of the will, its act, a world of strange new things, circumstances, even acts of will may be interposed without breaking this long chain of will" (GM II, 1). In this way, memory imposes a certain amount of order, regularity and predictability - a kind of lastingness - upon the self that is conditioned by our actions.

Yet the origin of memory, for Nietzsche, does not lie with the self. Rather, it is a stabilising force that arises within a human community and therefore establishes the self in relation to others. In the course of his analysis of punishment in The Genealogy of Morals, Nietzsche advances the thesis that the need to remember stems from an original need to honour contracts made, and that it is through the experience of corporeal punishment for failing to discharge our debts that we first acquire a memory ( $G M$ II, 1-3). In this way, pain functions as the original mnemonic device whereby we are moulded into beings capable of committing ourselves to the future, and punishment relates the self to the community to whom the debt is owed.

However, Nietzsche considers unbridled memory to be as destructive of the self as unremembered action. Boundless memory ties us to the past and precludes the sense of immediacy that is the condition of all action. This point recalls the famous dictum from The Gay Science that "by doing we forego" (GS 304), meaning that every action

4 In the case of The Genealogy of Morals, references are to the essay number followed by the paragraph number. 
irredeemably changes the course of events and therefore engenders the loss of other possibilities for action or valuation. Unconstrained memory would always remind us of this loss, and thus undermine the good conscience required to act at all. We need a measure of forgetfulness in order to perform the deeds by which we become who we are. This necessary forgetting can be likened to drawing a horizon around oneself, a kind of unhistorical armour, which shields us from doubt, and allows for the unconstrained conscience that is the condition for action in the present. Apart from its role in countering the passivity that comes with an excess of memory, forgetfulness also serves a further purpose as "a doorkeeper, a preserver of the psychic order, repose, and etiquette" (GM II, 1). The implication here is that any sense of self would be impossible if we were to know, in an absolute sense, everything about oneself. Certain truths must be veiled if the performance is to continue.

To summarise these preliminary insights into Nietzsche's portrayal of selfformation: one becomes a self by acting in the world; one remains a self by virtue of memory, which binds one act to another, thus producing an enduring character over time, while the capacity for action, as well as the sense of identity that emerges from such action, are both protected by a certain amount of forgetfulness. At this point, we are again confronted with the earlier question of how this particular conception of self-formation relates to Nietzsche's contention that the self is an illusion. An answer here requires a more detailed exploration of the worldly horizon that circumscribes human identity.

In an unpublished note from 1872 Nietzsche writes: "We know what the world is: absolute and unconditional knowledge is the desire to know without knowledge" (KSA VII.465; note 19 [146])..$^{5}$ If what counts as the world for us is merely conditional knowledge, what is the source of this conditioning? We are, claims Nietzsche, or rather, our need for a world in which it is possible for us to live. This domain is the phenomenal world that exists for $u s$, and which would disappear in the course of any successful attempt to do away with all appearance, fiction, and illusion and to find the unconditional basis of the world-in-itself. In a much later note, Nietzsche asks rhetorically: "Is not the world for us merely a combination of relations under a measure? As soon as this arbitrary measure is lacking, our world dissolves!" (KSA IX.454, note 11 [36]). This formulation suggests two important qualities pertaining to the world that concerns us: a relational quality and the quality of arbitrariness or provisionality. It is essential first to examine these two attributes in conjunction with one another, before turning to the implications of this conception of the world for our understanding of the self.

In the first place, the relational aspect of the world has bearing on Nietzsche's performative account of identity: action calls up witnesses, and thus brings the one who acts into a relation with others. ${ }^{6}$ Stated differently, to give form to a self requires an arena in which the performance can be played out, an inter-human horizon of meaning in which this self acquires significance and thus a form of endurance. This

5 For unpublished material from Nietzsche's notebooks, references are to the volume and page numbers in the Kritische Studienausgabe of Nietzsche's collected works, followed by the note number. In these cases, the translations are our own.

6 Nietzsche demonstrates how the meaning of an action changes in relation to a specific interpretative community (which impacts, in turn, on the way in which the relationships between the members of such a community are constituted) in his analyses of monumental, antiquarian and critical history in 'The Uses and Disadvantages of History for Life', 3). 
worldly domain can be understood as a "space of appearance" (Arendt 1958: 199 ff.) in which we encounter one another, become visible to one another, both as performers and as spectators of the performance. What we designate as the world is precisely this field of appearances and relations that conditions the belief in the self as a coherent entity.

In Nietzsche's account, this belief, and the conditions from which it springs, are necessary requirements for human life. Nevertheless, one should not confuse human necessity with truth. Nietzsche's concern is with the world in which it is possible for us to live - the world of appearances, which circumscribes the conditions under which we appear. ${ }^{7}$ The world in his sense is no thing in itself, but rather a necessary error that emerges from a combination of human need and creativity. In this respect, the human being can be understood as the measure of the world, but then only as an arbitrary measure. Our measurements or value-standards do not refer to an original reality, but merely to our contingent position within - and thus our limited perspective on - the relations that constitute the inter-human domain. At the same time, these positions and perspectives emerge from the interplay of these relations themselves. In this sense, we both give form to and are formed by the world that lies between us. Another note from the Nachlass describes this interplay between the self and world - or the part and the whole - as follows:

Every center of force adopts a perspective toward the entire remainder, i.e. its own particular valuation, mode of action, and mode of resistance. The "apparent world", therefore, is reduced to a specific mode of action on the world, emanating from a center.

Now there is no other mode of action whatever; and the "world" is only a word for the totality of these actions. Reality consists precisely in this particular action and reaction of every individual part toward the whole - (WP 567).

Starting from this formulation, it is possible to claim that what counts as the world for us is sustained by the ceaseless, dynamic interplay of forces that operate on one another by way of action and resistance - or, in Nietzsche's terms: the will to power. In his account, we ourselves are part of this force-field insofar as we interpret; that is to say, insofar as we mould the chaos of experience into a specific order for the sake of maintaining a particular form of life. In this respect, each interpreter is a centre of force, which exercises itself upon the totality of interpretations and evaluations that constitute the world. ${ }^{8}$ To interpret, in this sense, is not to come to know something about the world as thing-in-itself, but rather "to schematize - to impose upon chaos as much regularity and form as our practical needs require" (WP 515).

In Nietzsche's account, this schematization finds its most compelling expression in history - or the codification of memory - and language. If, as discussed in the previous section, memory allows identity to endure over time, then history relates the memory of the individual to that of the community, and in this way creates a stable world in which one can be recognised as a self in distinction from others. History and memory

7 "We have arranged for ourselves a world in which we can live - by positing bodies, lines, planes, causes and effects, motion and rest, form and content; without these articles of faith nobody would now endure life. But that does not prove them. Life is no argument. The conditions of life might include error" (GS 121).

8 This is precisely the point of the famed pronouncement that ' $[t]$ he world seen from within, the world described and defined according to its 'intelligible character' - it would be 'will to power' and nothing else' (BGE 36). 
are moulded in turn by the conceptual categories at our disposal which we share with one another. Yet while these shared linguistic categories may correspond to our practical needs, this is no proof of a reality that corresponds to the concepts we have at our disposal. On the contrary, Nietzsche claims that concepts only designate relations of things to ourselves (TL p. 82), and that every conceptual scheme - be it an account of the past, of the community or of the self - is therefore merely a contingent interpretation of a complex of forces and relations, not intimations of a given truth. Moreover, if every such interpretation takes place against the background of an endless play of interpretations, no single interpretation can lay claim to final validity. In this sense, the world is infinite, "inasmuch as we cannot reject the possibility that it may include infinite interpretations" (GS 374).

This insight relates to the second characteristic of the inter-human domain: its provisional character. For Nietzsche, the horizon of meaning within which we give form to ourselves is an indeterminate space, which retains its ambiguity over and against all attempts to inscribe it with a fixed character.

Clearly, to conceive of the world in this way has implications for our understanding of the self. In the first place, given that we are embedded in the complex of forces that sustains the domain of human life, it is senseless to think the self over and against the world. Nietzsche considers this a laughable juxtaposition, and goes so far as to describe the insertion of "and" between "human" and "world" as a "sublime presumption" (GS 346). The self, in his sense, is worldly: who one is, is embedded in the sum of temporal relations that conditions one's becoming anything at all.

The second implication is that self-formation does not equal self-knowledge. For, whereas each individual may well be a unique complex of drives or constitution of forces, we can only ever "know" ourselves by means of conceptual schemata we share with others, and that are therefore precisely not unique, but average, common and general. Since we lack the appropriate "sensitive organs" with which to grasp our inner world unmediated by language - which belongs to the external world - we cannot but "sense a thousandfold complexity as a unity" (WP 523). Stated differently: the self is constructed by its mode of knowing, yet this knowing takes place in categories that are not of our own making, and therefore reaches no deeper than "a groping game on the backs of things" (TL p. 80).

The last and most significant implication is that the Nietzschean self is not a unitary entity, but a plurality. If the form one gives to oneself is nothing more than a changeable interpretation of the interplay of forces that constitute the world, then every conception of the self bears traces of dissonance, of the untold permutations of force that cannot be incorporated into a finite account of a single life. Here we should also recall the characterisation of the self as an organisation of drives or forces, an interpretation of the body, that is nevertheless not a fixed or complete manifestation of its physiological source. In Nietzsche's phrasing, the self is therefore always an imperfect tense that can never become a perfect one; a sum with an awkward fraction left over (UDH 1).

The important question in this regard - important in a moral and political sense - is how we deal with this sense of disunity and incompleteness. Broadly speaking, Nietz-

9 Consider also: 'I maintain the phenomenality of the inner world, too: everything of which we become conscious is arranged, schematized, interpreted through and though - the actual process of inner 'perception', the causal connection between thoughts, feelings, desires, between subject and object, are absolutely hidden from us - and are perhaps purely imaginary. The 'apparent inner world' is governed by just the same forms and procedures as the 'outer' world' (WP 477). 
sche identifies three possible strategies of response. The first strategy is simply the forceful denial or suppression of all dissonance in favour of belief in the unitary self, which includes holding fast to an absolute distinction between self and world. A second option is to surrender to the ceaseless movement of the chaotic and disparate forces that rend asunder all identity. Both of these belong in the land of the cannibals, for they both destroy the worldly conditions under which we are able to give form to ourselves - albeit in different ways. The unitary conception of the self seeks its meaning in a fixed point that necessarily lies outside the changeable human world, thereby severing its adherents from the inter-human domain and casting them back upon themselves, while the thoughtless surrender to a chaotic array of values, beliefs and practices results in a kind of unlimited internal warfare that consumes all coherent identity.

In contrast to these two self-destructive attempts at dealing with the disunity and contradiction that springs from our embeddedness in the world as will to power, Nietzsche advocates an alternative strategy which he designates as "the art of dividing without making inimical; mixing up nothing, "reconciling" nothing; a tremendous multiplicity which is nonetheless the opposite of chaos" (EH: "Why I am so clever", 9). To give form to a self in this sense is neither to suspend the play of dissonance in favour of a static unity, nor to surrender to the pull of a chaotic array of forces, but to act under the constraint of style. Whatever identity is formed in this fashion would encompass the tension between constraint, order, rhythm and the excess of possibilities for action arising from the amorphous force-field that is the will to power. Nietzsche designates this performative identity as "dancing in chains" (WS 140), comprising both fluidity and self-control, dynamis and restraint. Such a performance would sustain the proportional relation between action, memory and forgetfulness, and in this way would constitute the masterly art whereby "one neither goes wrong nor hesitates in the performance" (GS 537). ${ }^{10}$

Against this background, it is possible to make sense of Nietzsche's dual emphasis on the need for self-formation and the illusory nature of the self. His point is that, while the self may be a contingent structure, a changeable organisation of forces, the mode of organisation matters - and, as we shall see, matters ethically. Before attempting an exposition of this point, however, it is important to first examine the argument about the formation of the self that can be made from the perspective of complexity theory. The following section introduces an understanding of the self as a complex system which shows a demonstrable affinity with the insights offered by Nietzsche, before the final section draws together the most important threads running through both descriptions in a consideration of the ethical-political dimensions of the self.

10 It is important to note that, for Nietzsche, the style of individual self-formation is conditioned by the cultural complex from which it emerges. For presicely this reason, a Caesar, a Goethe, a Napoleon - some of Nietzsche's examples of human beings in the "grand style" - are no longer possible today: the cultural constellations that made them possible no longer exist. For Nietzsche's understanding of culture as the groundwork of individual existence, see Van Tongeren (2000). 


\section{Complexity theory and the self}

Before turning to a discussion of the self from a complexity perspective, it may be useful to introduce some of the basic principles of complexity theory. ${ }^{11}$ Complexity theory studies systems. Where classical physics would approach a complex system in a reductionist fashion, ${ }^{12}$ complexity theory takes, as far as possible, the relational character of the constituents of complex systems into account. One cannot analyse all the parts that make up a system separately in the hope that this will capture the essence of the system. Because the characteristics of the system are established in the relationships between the components, we destroy such characteristics (often called emergent properties) when we "cut up" the system. Since emergent properties are the result of the interactions in the system, they cannot be predicted merely by an examination of the separate components of the system. What is more, since the interactions are non-linear (Cilliers 1998: 4, 120), we cannot replace a specific set of interactions with another, simpler set of interactions. Complexity is incompressible (7-10). This is another way of saying that a complex system cannot be broken up into its constituent parts, nor can it be replaced by a simpler system, without losing vital characteristics of the system. Since all descriptions (or models) of complex systems must reduce the complexity in order to be intelligible, we can conclude that formal, a priori models of complex systems (like the self) can never be final or complete (Cilliers 2001).

When examining a complex system we have to consider not only the set of relationships which constitutes the system, but also the environment in which the system has to function. ${ }^{13}$ The intricate interaction between the system and its environment means that it is often difficult to determine the borders of the system. A complex system is thus not merely a passive reflection of its environment, nor is it in control of the environment. The relationship between the two involves a dialectic that is neither active nor passive. ${ }^{14}$ The environment is usually complex in itself, and in order to cope, a complex system needs to be able to do two things: it needs to be able to store information about its environment (memory), and it needs to be able to adapt its structure to changes around it.

Specific adaptations to a changing environment cannot be programmed into the system, nor can the system act according to inherent or a priori principles which do not take the external world into account. In order to deal with contingencies, the system has to be able to organise itself. This self-organisation relationally incorporates the history of the system (memory) and elements external to it (Cilliers 1998: 89-111).

11 Some aspects of complexity theory may have developed out of chaos theory, but complexity is most certainly not reducible to (deterministic) chaos. The way in which Nietzsche uses the notion "chaos" has absolutely nothing to do with chaos theory. A detailed description of complexity from a philosophical perspective is provided in Cilliers (1998). Other sources with introductions to complexity and discussions of its implications in various contexts include Juarrero (1999), Prigogine and Stenger (1984), Kaufmann (1995), Lewin (1993) and Khalil and Boulding (1996). The problem of the self is explored in greater detail in Cilliers and De Villiers (2000).

12 Prigogine and Stenger (1984:7) use the metaphor of reducing a building to a pile of bricks, in the sense of not being able to see the building for the bricks, to describe this reductionist method.

13 When talking about the self, the term 'environment' refers to the complete collection of influences that the self is, and has been, exposed to: other people, the media, objects that it encounters, its own history, memories, perceptions, physical sensations etc.

14 This dynamic is captured best by Derrida's notion of différance. The affinities between complexity and post-structural theories are discussed at length in Chapter 5 of Cilliers (1998). 
The most important characteristics of complex systems can, for our purposes be summarised in the following way:

i) A complex systems consists of a large number of elements.

ii) The elements of a complex system are in dynamic interaction. This interaction is non-linear and need not necessarily be interpreted in a physical sense; they could also be thought of in terms of transference of information.

iii) Complex systems are open systems. They interact with their environment and it often becomes difficult to define the borders of a system. The limits of a system are usually imposed on it by our description of it, not by some natural feature of the system. This is referred to as the problem of framing.

iv) Complex systems have memory. They evolve through time, their history is co-responsible for their internal structure and therefore also for their present behaviour.

In what follows we argue that the self can be understood as a complex system, something that is not pre-formed, but comes to be in social interaction. In order to survive, it must be able to adjust to its environment. The environment is also historically determined in a contingent way. The self has to operate within the structures and constraints provided by the environment. At the same time, it actively participates in, and thereby transforms the environment. We are therefore not born pre-programmed with an inherent idea of what it means to be human, nor with a fixed idea of what the world itself is and how it should be dealt with. These ideas have to be developed through an engagement with the world. We act upon the contingencies that form part of daily life by means of a dynamic interaction between new information and previous experience. In this way our "memory" of what we are is constantly changed. If this argument is to have any power, we will have to show that the different characteristics of complex systems (discussed above) are relevant to an understanding of the self.

If we think of the self as something that is constituted in a system of (social) relationships, then a large number of elements are certainly involved. What is more, each self is not a unitary thing, but made of many different sub-components constituted through the traces of experienced interaction. This is not a claim for inherent schizophrenia, but rather an acknowledgement of the divided, even contradictory nature of personhood. This complex nature is a result of the complex environment in which the self is formed. One cannot assimilate the whole array of influences (other people, conversations, books, our education, our material circumstances, state of bodily health, our childhood memories and future prospects; in other words life, the universe and everything) into one, neat, coherent package. ${ }^{15}$

15 At this point the similarity with a post-modern rejection of coherent meta-narratives should be obvious. The argument from complexity is however never an argument for relativism - cf. Cilliers (1998: 21-23, 136). Lyotard (1984: 15) provides the following description of the self:

A self does not amount to much, but no self is an island; each exists in a fabric of relations that is now more complex and mobile than ever before. Young or old, man or woman, rich or poor, a person is always located at 'nodal points' of specific communication circuits, however tiny these may be. Or better: one is always located at a post through which various kinds of messages pass. No one, not even the least privileged among us, is ever entirely powerless over the messages that traverse and position him at the post of sender, addressee, or referent. One's mobility in relation to these language game effects (language games, of course, are what this is all about) is tolerable, at least within certain limits (and the limits are vague); it is even solicited by regulatory mechanisms, 
The self cannot be meaningful in isolation. The self is constituted by its relationships to others and the world. Our environment (context) is continually shifting and changing and we need to adjust the sense we make of it and of ourselves. The effects of these interactions are also not predictable. Things which seem important may turn out to be insignificant, and vice versa. This is a result of the non-linearity of the interactions: small causes can have large effects.

The self is an open system. It is impossible to point to some precise boundary where "we" stop and where the world begins. To confine the self to the prison of the skull is a gross oversimplification; it is a space in which the body and the life world (nature and culture) intertwine.

The self is a result of its history. No two people can have identical histories or find themselves in identical contexts. Even with apparently very similar backgrounds, the non-linear interactions amongst the host of other factors which form and maintain the self would make them different. Although the self is in a way nothing more than the sedimentation of its history in memory, history is not a simple causal force. The self is therefore neither an arbitrary construct, nor a fully determined entity. It is constituted by its own unique and contingent history and context.

To summarise, the self is not a complete and coherent entity present to itself. It is constituted through the complex interaction amongst a host of factors, the significance of which cannot be pinpointed with finality. Our sense of self is the result of transient patterns in this network of traces. Consciousness is an emergent property of this network, not a central control system that "causes" the experience of the self. Viewing the self as relational makes for a more flexible way of understanding how we come to be who we are. Despite the fact that the self is not fully determined, it is still quite possible to talk about someone's identity or beliefs in a meaningful way. By arguing that identity cannot be fixed, we are not suggesting that identity is fragmented and arbitrary. A complex system is neither homogeneous nor random; it has structure, even if this structure is continuously transformed. Just as words cannot have meaning if they are not repeatable or iterable, ${ }^{16}$ the structures in a complex system must be identifiable. Transformation cannot be other than the transformation of something specific into something which can be recognised as a new form of the previous structure. There is thus no contradiction involved if we deny an essentialist understanding of the self, but still talk of someone's "identity". However, this identity cannot be separated from its embeddedness in social conditions, and will therefore always have a political dimension. This aspect will receive attention in the final section.

\section{"Ethics" and the complex self}

The formation and development of the self cannot be understood in isolation of the social domain. This entails that ethical and political considerations are always at stake, albeit not "ethics" in the normative or middle-class sense of the word. The argument is not that we can deduce a certain ethical framework within which the self should func-

and in particular by the self-adjustments the system undertakes in order to improve its performance. It may even be said that the system can and must encourage such movement to the extent that it combats its own entropy; the novelty of an unexpected 'move', with its correlative displacement of a partner or group of partners, can supply the system with that increased performativity it forever demands and consumes.

16 Derrida's essay Signature Event Context, as well as the important Afterword to Limited Inc provides a backdrop to the argument here (see Derrida 1988). 
tion, nor do we argue for a set of ethical criteria which would identify a self as being "authentic". The kind of ethics we argue for has more to do with the inevitability of choice. The use of the notion "choice", however, does not refer to choices made in absolute freedom, but to choices made within a network of social constraints. The dilemma of being responsible for your choices whilst at the same time not being totally free to make them, is already alluded to in the aphorism concerning the land of the cannibals. We will return to how this ethics works in a Nietzschean way after we have examined what it means in the context of complexity.

We have argued above for the incompressibility of a complex system. This means that a complex system cannot be replaced with something which is simpler without distortion. We have also argued that complex systems are open systems, that is, that it is not possible to define the boundaries of a system clearly. When we deal with a complex system, we have to deal with its environment as well - system and environment are not clearly separable. When we try to describe or understand a complex system, it is never self-evident what should be included and what not. For a complete understanding, we would have to include everything. Under finite conditions (like being human), we cannot do that. We have to choose what is going to be included in the description and what not. There is no resort to a transcendental viewpoint which can determine those choices. This does not mean that we can escape choice. When we try to understand something complex, we have to reduce the complexity in order to bring it within our grasp - there is no other choice. We are doomed to make choices; distortions are an inevitable part of the attempt to describe the world. The choices we make can, however, not be purely arbitrary. The complexity we are trying to understand is not featureless. There are patterns and structures which constrain our descriptions. We cannot find a pure description, and at the same time we cannot just come up with any description. The strategy behind the description forms part of the description. Since our descriptions are never purely objective, we are responsible for them. ${ }^{17}$

In order to give some substance to this "ethical" understanding of the self, we can look at a number of specific characteristics following from complexity (as discussed in the previous section):

1. The self is constituted relationally. It cannot be conceived of in isolation. This does not mean that it has no identity. The identity of a certain, singular self is constituted by the pattern of relationships pertaining to that self. The relationships are mostly with other selves which are also constituted relationally. ${ }^{18}$

2. The set of relationships at stake is contingent, not metaphysically determined. The differences which exist among selves - and there are differences - are also the result of contingent, not a priori, factors.

3. The formation of the self is a dynamic process which does not terminate in some form if completeness is reached. The self is therefore always "still to come". What we have at any given point is provisional.

4. The set of relationships at stake is a result of the specific history of a certain self. Relationships are sedimented in memory traces. Since these traces are all overlapping and interacting (the self is a palimpsest), the history of the self is not a clear

17 See Cilliers $(2000,2001)$ for a more detailed argument.

18 This is equivalent to a kind of Saussurian system of signs. For a discussion of the similarities between complexity and structural/post-structural descriptions, see Cilliers (1998: 37-47). 
determining force. Some traces are reinforced, others fade away. Memory and forgetting go hand in hand. ${ }^{19}$ The self is nothing but its history, but its history cannot be decoded into a single, well-structured narrative.

5. The pattern of relationships is not fully integrated into a unitary whole at any specific moment in time either. This means that more than one perspective on the self is possible. It cannot be reduced to something essential which can be captured with a single description. Different aspects of the self are activated in different contexts.

6. The self is not transparent to itself. In other words, the self is not a homunculus located somewhere inside. The contingent, historical and relational nature of the self implies that the self discovers itself in space and time - the self emerges from its actions, not from some essential description of what it is or should be. This is not an argument for a discontinuous self, but for the fact that the self cannot escape its own complexity. ${ }^{20}$

7. This adds up to a self that is somehow fragile and robust at the same time. It is fragile in the sense that it can be altered drastically through experience, but since it is a relational - not an essential - entity, there is no core that can be destroyed. The self can thus maintain an identity which under normal circumstances will remain stable, but when placed under pressure, can be transformed. Finding a balance between stability and change is part of the process of forming a meaningful self - one that is neither stagnant nor at the mercy of every flutter in the environment.

From the complexity perspective, the self can, in summary, not be seen as selfidentical or essential. It comes to be through dynamic interaction with the environment and other selves. These interactions are "sedimented" in time - the self is a product of its history. Nevertheless, the self is not fully determined, not by its history, nor by its present, contingent situation. The patterns of interaction constituting the self are too complex to be reduced to something singular. Yet, when we try to understand or evaluate ourselves and others, we have to perform a kind of reduction. This reduction cannot be made objectively, and therefore we inevitably have to deal with an ethical dimension. We cannot give a complete, formal description of a complex system in terms of a finite set of rational principles, which means that when we deal with complex things, like human subjects, we cannot get by with calculation alone. We have to make use of frameworks and assumptions. Since there are no meta-rules which supply these frameworks, we have to make choices based on values, rather than on rational knowl-

19 The ability to forget is a pre-requisite for the ability to remember traces in a complex network of relationships. See Cilliers (1998: 45-46, 92).

20 This intransparency is one of the central issues in a Freudian understanding of the self, also emphasised by Nietzsche in 'On Truth and Lie In a Non-Moral Sense' (p. 80) in the following way:

What does man actually know about himself? Is he, indeed, ever able to perceive himself completely, as if laid out in a lighted display case? Does nature not conceal most things from him even concerning his own body - in order to confine and lock him within a proud, deceptive consciousness, aloof from the coils of the bowels, the rapid flow of the blood stream, the intricate quivering of the fibres! She threw away the key. And woe to that fatal curiosity which might one day have the power to peer out and down through a crack in the chamber of consciousness and then suspect that man is sustained in the indifference of his ignorance by that which is pitiless, greedy, insatiable, and murderous - as if hanging in dreams on the back of a tiger. Given this situation, where in the world could the drive of truth have come from? 
edge or the outcome of calculations. Another way to formulate this is to say that we are always already in the realm of ethics. Since we cannot shift the responsibility for our decisions onto any fixed or given procedure, we have to assume that responsibility. Yet such responsibility for our decisions and actions, including their impact on the lives of others, is not a burden we have to bear; it is what makes us who we are.

This simultaneous indeterminacy and inescapability of ethics in relation to the self may be clarified through a further consideration of the notion of the will to power that was introduced in section one. Will to power, for Nietzsche, may be understood as the quality (as opposed to "essence") of irresolvable tension and contest between the constellations of forces that constitute the world. The will to power in this sense "is not a being, not a becoming, but a pathos - the most elemental fact from which a becoming and effecting first emerge -" (WP 635). This pathos (occasion, passion, suffering) is precisely not a state, an entity, the unchanging substratum upon which the changing, apparent world is erected. Rather, the will to power describes the quality of the ceaseless struggle between what Nietzsche calls "dynamic quanta", each of which only exists by virtue of its relation to all other dynamic quanta (ibid.). These power quanta "do not first exist for themselves and then enter a relationship with one another. They exist only in the (incessantly changing) referentiality of all to all" (Müller-Lauter 1999:15), and it is the mutual struggle or antagonism inherent in this referentiality that conditions the emergence of all events (ibid:13).

Given this understanding of the will to power, the self is not a "thing" among other things in the world, but an emergent property of the dynamic constellation of forces that is the will to power. For Nietzsche, contrary to the essentialist understanding of the self as a pre-formed subject which first exists, and then engages in a number of activities, some of them belonging in the realm of ethics and others not, the self as a constellation of will to power is always already engaged in moral evaluation. Every experience of the world, in so far as it becomes conscious, is already a rank-ordering, a choice for one possible interpretation of the world amidst an infinite range of possible interpretations. To interpret is to set up a certain way of seeing, a certain way of knowing on the basis of an evaluation of what is worth seeing and worth knowing. In this regard, "All experiences are moral experiences, even in the realm of sense perception" (GS 114); every perspective on the world is already a value judgment.

For Nietzsche, although our judgments are only interpretations, we remain responsible for them, not in the sense of being autonomous agents who freely choose their beliefs and practices and therefore cannot blame any other agency for these choices, but in the sense of being inextricably bound up with, and thus responsible for, the world which both forms and is formed by our interpretations. This embeddedness can be understood as an "illogical original relationship with all things" (HAH I, 31), whereby every interpretation is neither a function of a self-sufficient subject-identity nor simply causally determined by forces outside the self, but a "quantitative particularization" of the will to power (Müller-Lauter 1999: 133). Nietzsche describes this particularisation as a "complex form of specificity" or "perspective" which, by virtue of its contingent position within a complex of relations can never encompass all possible interpretations of the world (WP 636). The kind of divine understanding that would comprehend existence as a whole, cannot but elude the contingent self, who therefore has to 
learn to grasp the sense of perspective in every value judgment - the displacement, distortion and merely apparent teleology of horizons and whatever else pertains to perspectivism; [...] the necessary injustice in every For and Against, injustice as inseparable from life, life itself as conditioned by the sense of perspective and its injustice ( $H A H \mathrm{I}$, Preface 6).

This acknowledgement of the impossibility of a just evaluation of the world, coupled with the inevitability of judgment, has a number of ethical-political implications. Nietzsche's conception of both self and world recognises that no perspective, no singular identity, can ever reflect the entire dynamics of the world as will to power, and that any "order" we might impose upon the world is a particular, changeable interpretation that is always open to resistance and subversion. This recognition therefore implies that there is a limit to what we can "know" about the self and about the world which conditions the self. The metaphysical inheritance of modernity, by contrast, acknowledges no such limit: it rests on the presumption of an ideally ordered world, or at least a world susceptible to the order we impose upon it. This presumption of order, either as reality or as future achievement, conditions the belief that anything that hints at disorder, excess, or resistance stands in need of suppression, exclusion or punishment. This presumption also relies on a supposedly "neutral and objective" view of the self which in fact does violence to the subject in question. It disregards crucial components of what makes up a person. It leads to a kind of "colonisation" of subjects: "we know what a subject is, therefore we know what you really are, and therefore we know how to treat you". These violations do not only affect the others in question, but ultimately also those who commit the violation. Such an approach leads to a disregard of difference, to a social homogenisation, and therefore to an impoverished environment. Since we can only come to be within a social environment, a poorer, or less complex, environment will deprive those who live in that environment of certain possibilities. Yet, the fostering of difference will yield the opposite result. ${ }^{21}$

Nietzsche, in dealing with difference in the context of social organisation, consistently identifies the most important quality of such organisation as the "pathos of distance" (cf. especially BGE 257; TI IX, 37) - literally, the sense of remoteness or distinctness from one another that is nevertheless a precondition for communality. In a telling aphorism from Human, All Too Human, he expresses the relationship between these two poles as follows: "[i]t is not in how one soul approaches another but in how it distances itself from it that I recognize their affinity and relatedness" (HAH II, 251). The point here is that our "affinity" or sense of communality - in other words, the acknowledgement of our embeddedness within a network of inter-human relations - depends precisely upon the recognition of our differentiation. Homogenisation, or any notion of communality based upon the belief in "similar souls" existing apart from any social differentiation, limits the possible ways of conceiving of oneself as well as relating to others. In Nietzsche's account, this limitation is primarily a condition for the oppression of the unvaried subjects of mass society: beings who are "wholly structure,

21 This is not to say that this alternative understanding of the self is necessarily a democratic one, at least not in the sense intended by standard liberal democratic theory. In Nietzsche's case especially, democracy itself is open to questioning in so far as it fails to acknowledge - even more, to stimulate - an unresolvable contest between individuals (cf. HAH I, 472; GS 356; BGE 202). However, as it is not the purpose of this article to develop a theory of democracy, these considerations lie beyond the scope of our investigation. 
image, form without demonstrable content and, unhappily, ill-designed form and, what is more, uniform" (Nietzsche UDH 5). ${ }^{22}$ Against this background, the undetermined, contingent self advocated by Nietzsche and supported by the arguments from complexity theory constitutes a counter-force to the forms of political domination that is exercised over what is assumed to be an homogenous or amorphous social body.

An emphasis on the political dimension of the complex self reminds us of the inevitability of ethical involvement. We are formed by our interventions in the world (or lack of them), while also shaping others by them. We are not completed subjects who have to make decisions and act upon them. Rather, we, and the worldly domain in which we exist, come to be through those decisions and actions, while the choice to abstain from certain actions is an equally formative ethical-political choice.

It is our contention that this understanding of the self that derives from the respective arguments drawn from Nietzsche and complexity theory provides a counterweight to the cannibalism of unqualified privacy or collectivity. We have tried to show in this paper how these arguments converge in a specific attempt to represent the disunity and contradiction that spring from our embeddedness in the world in a way that neither suppresses any intimation of complexity in favour of an essentialist notion of the self, nor dissolves all coherent identity into endless, arbitrary movement. Such a conception of the self allows for a consideration of the extent to which we exist within a contingent network of relations to which we nevertheless remain bound in every attempt to become what we are. This network is precisely what lies between the self and the crowd; it is what both binds us together and differentiates us from one another; the condition for both affinity and distance.

To conclude: At the meeting point between Nietzsche and complexity theory lies a conception of a dynamic, worldly self that is neither arbitrary or subjective, nor bound by fixed, objective rules - a fragile self, in other words, that exists within the tension between unity and dissonance, order and multiplicity, solitude and communality. This understanding of the self is not merely of academic interest; it has both ethical and political significance. At the centre of this perspective stands consideration for the worldliness of human existence: the fact that who one is - the question of self - is bound up with a world shared with others. The self, in other words, is always embedded in human communality, and only exists within a network of human relations. Both sets of arguments have shown that this network is not a fixed structure, but rather circumscribes a domain of worldly engagement that is characterised by provisionality, heterogeneity and complexity. On this view, we are unavoidably implicated in the fragile realm of human affairs, so that to give form to a self is intrinsically linked to sustaining a human world in which we exist in the plural.

\section{Bibliography}

Arendt, H. 1958. The Human Condition. Chicago: University of Chicago Press.

- 1976. Origins of Totalitarianism. New York: Harcourt Brace.

Cilliers P. 1998. Complexity and Postmodernism: Understanding complex systems. London: Routledge.

22 This argument finds similar expression in Hannah Arendt's analysis of totalitarian domination as predicated on the existence of a mass of undifferentiated, yet unrelated subjects. See in this regard Arendt (1976: 457) and (1958: 52-53). 
- 2000. What Can We Learn From a Theory of Complexity? Emergence, 2000, Vol. 2(1).

- 2001. Boundaries, Hierarchies and Networks in Complex Systems. International Journal of Innovation Management, Vol. 5, No. 2, June 2001.

Cilliers, P. and De Villiers, T. 2000. The Complex "I", in The Political Subject, edited by W. Wheeler, London: Lawrence \& Wishart.

Derrida, J. 1988. Limited Inc. Evanston: Northwestern University Press.

Juarrero, A. 1999 Dynamics in action. Intentional behaviour as a complex system. Cambridge, MA: MIT Press.

Kauffman, S.A. 1995. At home in the Universe. The Search for Laws of Complexity. London: Viking Press.

Khalil, E.L. and Boulding, K.E. (eds.) 1996. Evolution, Order and Complexity. London: Routledge.

Lewin, R. 1993. Complexity. Life on the Edge of Chaos. London: Phoenix.

Lyotard, J.F. 1984. The Postmodern Condition: A Report on Knowledge. Manchester: Manchester University Press.

MacIntyre, A. 1992. After Virtue. A Study in Moral Theory. London: Duckworth.

Müller-Lauter, W. 1999. Nietzsche. His Philosophy of Contradictions and the Contradictions of His Philosophy, trans. D.J. Parent. Illinois: Univ. of Illinois Press.

Nietzsche, F. 1968. The Will to Power (WP), trans. W. Kaufmann and R. J. Hollingdale, ed. W. Kaufmann. New York: Vintage Books.

- $\quad$ 1968b. Twilight of the Idols (TI), trans. R.J. Hollingdale. Harmondsworth: Penguin.

- 1973. Beyond Good and Evil (BGE), trans. R.J. Hollingdale. Harmondsworth: Penguin.

- 1974. The Gay Science (GS), trans. W. Kaufmann. New York: Random House.

- 1979. Ecce Homo (EH), trans. R. J. Hollingdale. Harmondsworth: Penguin.

- 1982. "On Truth and Lie in a Non-Moral sense" (TL), trans. D. Breazeale. In Breazeale, D. (ed.) Philosophy and Truth. New Jersey: Humanities Press.

- 1983. "On the Uses and Disadvantages of History for Life" (UDH) in Untimely Meditations, trans. R. J. Hollingdale. Cambridge: Cambridge University Press.

- 1986. Human, All Too Human, Vols. 1 \& 2 (HAH I and II), trans. R. J. Hollingdale. Cambridge: Cambridge University Press.

- 1986. "The Wanderer and His Shadow" (WS) in Human, All Too Human, Vol. 2, trans. R. J. Hollingdale. Cambridge: Cambridge University Press.

- 1988. Sämtliche Werke: Kritische Studienausgabe in 15 Bänden (KSA), ed. G. Colli \& M. Montinari. Berlin: De Gruyter.

- 1989. The Genealogy of Morals (GM), trans. W. Kaufmann and R. J. Hollingdale. New York: Vintage Books.

Prigogine, I. and Stenger, I. 1984. Order out of Chaos. Man's New Dialogue with Nature. London: Heinemann.

Van Tongeren, P.J.M. 2000. Reinterpreting Modern Culture, An Introduction to Friedrich Nietzsche's Philosophy. Indiana: Purdue University Press.

Villa, D.R. 1992. "Beyond Good and Evil: Arendt, Nietzsche and the aestheticization of political action.” In Political theory Vol. 20 No. 2, pp. 274-308. 